\title{
Molecular Detection of Sexually Transmitted Infections in Women with and without Human Papillomaviruses Infection Who Referred to Tehran West Hospitals in Iran
}

\author{
Seyed Mojtaba Mortazavi ${ }^{1}$, Amin Tarinjoo $^{2}$, Sepideh Dastani ${ }^{3}$, \\ Majid Niyazpour ${ }^{4}$, Samira Dahaghin*3 ${ }^{\text {, Reza Mirnejad*5 }}$
}

\begin{abstract}
Background: According to the studies, many pathogens function as cofactors interacting with Human papillomavirus in the development of pre-cancer or cancer of the cervix. The aim of this study was to investigate the prevalence rate of Sexually Transmitted Infections (STIs) pathogens including Mycoplasma hominis, Ureaplasma urealyticum, Chlamydia trachomatis, Neisseria gonorrhoeae, Gardnerella vaginalis, and Streptococcus agalactiae in people with HPV and without HPV infection, and frequency rate of these pathogens in high and low risk of HPV.

Methods: Cervical samples of 280 women who referred to Tehran west hospitals in Iran, between 2019 and 2020, were collected. After DNA extraction of samples, identification of HPV and genotyping was performed, and then, to detect each microorganism, the PCR was carried out with specific primers. Finally, the results were analyzed using descriptive statistics tests.

Results: The mean age of patients was 37 years. Two groups of patients were identified based on positivity or negativity of HPV. In HPV-positive group (118 cases), the prevalence of $U$. urealyticum, M. hominis, N. gonorrhoeae, G. vaginalis, and S. agalactiae was 38 (13\%), 7 (62\%), $5.93 \%, 19.49 \%, 0.84 \%$ respectively. In HPV-negative group (162 cases), rate of infection with $U$. urealyticum, M. hominis, N. gonorrhoeae, G. vaginalis, and S. agalactiae was $29.62 \%, 6.17 \%$, $3.08 \%, 16.04 \%, 0.61 \%$ respectively. Among the two groups, there was only 1 patient with $C$. trachomatis $(0.84 \%)$, seen in HPV-positive group.

Conclusions: In this study no significant association was found between HPV and bacteria such as G. vaginalis and S. agalactiae, and it was found that C. trachomatis, and especially N. gonorrhoeae are strongly associated with HPV infection.
\end{abstract}

Keywords: HPV, Sexually transmitted infections, PCR.

\section{Introduction}

Human papillomaviruse infection is very common and human papillomaviruses are causative agents which have small double- stranded DNA belonging to the family Papillomaviridae. They infect squamous epithelia and develop proliferative lesions and

1: Student Research Committee, School of Medicine, Bam University of Medical Sciences, Bam, Iran.

2: Islamic Azad University, science and research branch, Tehran, Iran.

3: Department of Microbiology, Faculty of Advanced Science and Technology, Tehran Medical Sciences, Islamic Azad University, Tehran, Iran.

4: Tehran Azadi Pathobiology Laboratory.

5: Molecular Biology Research Center, Systems biology and poisonings institute, Baqiyatallah University of Medical Sciences, Tehran, Iran.

*Corresponding author: Samira Dahaghin; Tel: +98 21 7554568; E-mail: sa.dahaghin@gmail.com

\& Reza Mirnejad; Tel: +98 21 87554568; E-mail: rmirnejad@yahoo.com.

Received: 15 Nov, 2020; Accepted: 13 Dec, 2020 
skin warts. Almost 130 types of HPV have been identified that, depending on their oncogenic potential, are divided into high-risk and low-risk groups (1). High-risk group is oncogenic and low-risk group is non-oncogenic genotypes. The low-risk HPV is associated with benign or less malignant genital warts, but high-risk HPV is the major risk factor in the development of anogenital malignancies, specially cervical intraepithelial neoplasia and cervical cancer, if it is persistent (2-4). Human papillomaviruse infection also is one of the risk factors in sexually transmitted diseases which can be transmitted by sexual contacts between humans. Also, other genital microorganisms including Neisseria gonorrhoeae, Chlamydia trachomatis, group B streptococcus, Mycoplasmas, Gardnerella vaginalis, Herpes Simplex Virus (HSV), and Human Immunodeficiency Virus (HIV), can cause sexually transmitted infections (STIs). Infections with these microorganisms also can have serious consequences (5-8). According to the studies, many pathogens, including $C$. trachomatis and Ureaplasma urealyticum, serve as cofactors interacting with HPV in the development of pre-cancer or cancer of the cervix. These agents by producing metabolites or carcinogenic substances, or increasing the susceptibility of the inflamed epithelium, disturbance of normal cellular metabolism, and damage to DNA, are directly or indirectly responsible for the development and progression of cervical lesions $(9,10) . M$. hominis and $U$. urealyticum belong to the Mollicutes class and Mycoplasmataceae family which can be considered as commensal of the female genital tract or pathogen $(11,12)$. They are the smallest organisms, having free-life and lacking a cell wall (13). M. hominis is associated with bacterial vaginosis (BV), Pelvic inflammatory disease (PID), cervicitis and endometritis (11) and $U$. urealyticum is associated with pregnancy abnormalities and infertility (12). C. trachomatis and $N$. gonorrhoeae are gram-negative bacteria and intracellular pathogens. $N$. gonorrhoeae can lead to serious disease including gonorrhea, pelvic inflammatory disease, infertility, ectopic pregnancy and urethritis. C. trachomatis has several serovars; A-C, D-K and L1-L3 serovars are associated with trachoma, urogenital infection and invasive lymphoma granuloma venereum (LGV), respectively $(14,15)$. Streptococcus agalactiae is also involved in genital infections. These gram-positive diplococcic are being colonized in genital area or rectum and invasive infection with them causes substantial morbidity and mortality (16, 17). G. vaginalis is a gram-variable, small, and normal flora of women vagina associated with $\operatorname{BV}(18,19)$.

Although for detection of these bacteria, the culture is golden standard, but it is difficult, and requires special culture media and a long time. Among methods of diagnosis, Polymerase Chain Reaction (PCR) is fast, sensitive, specific, easy for specimen transport and able to differentiate among various species $(20,21)$.

The purpose of this study was to investigate the prevalence rate of STI pathogens including $M$. hominis, $U$. urealyticum, $C$. trachomatis, $N$. gonorrhoeae, G. vaginalis and S. agalactiae in people with HPV and without HPV, and frequency rate of these pathogens in high risk and low risk of HPV.

\section{Materials and Methods}

The study population consisted of 280 women at the age of 18-59 years (mean age was 37) who referred to Tehran west hospitals in Iran, between 2019 and 2020. Written informed consent was obtained, according to the protocol approved by the Ethics Committee for Student Research Committee of Bam University of Medical Sciences (Code of Ethic: IR.MUBAM.REC.1398.004). All participants completed the questionnaire that included items on age, smoking, marital status, and history of pregnancies. Cervical brush samples were collected by a gynecologist and each of the samples was placed in phosphate buffer solution (PBS), transported to laboratory, and immediately placed in the freezer at $-80{ }^{\circ} \mathrm{C}$. DNA of samples were extracted according to kit manufacturer instructions (Qiagen, Germany) and stored at $20{ }^{\circ} \mathrm{C}$. 
Based on the study of Finan et al., immunohistochemistry of cervical smears was used to subdivide the specimen into two groups: HPV-positive group and HPVnegative group. Also, to confirm HPV identification, PCR using the MY09/MY11 primer system was applied as the gold standard (22).

Then HPV genotyping from samples also was performed using an HPV genotyping Test Kit (Master Diagnóstica, Granada, Spain). This kit can determine 36 HPV types including High risk HPV: $(16,18,26,31,33$, $35,39,45,51,52,53,56,58,59,66,68,73$ and 82$)$, and low risk HPV: $(6,11,40,42,43$, $44,54,55,61,62,67,69,70,71,72,81,84$, and 89 ).

To detect each microorganism in HPVpositive and HPV-negative specimens, the PCR was performed with specific primers. The sequences of primers for each microorganism are listed in Table 1. Amplification reaction was performed in a volume of $25 \mu \mathrm{l}$ and contained $12 \mathrm{ml}$ master mix (Ampliqon Co, Skovlunde, Denmark), $0.5 \mathrm{ml}(20 \mathrm{pmol})$ of each forward and reverse primer, $10 \mathrm{ml}$ sterile distilled water, and $2 \mu \mathrm{l}$ extracted DNA. The PCR reactions for these microorganisms were run by PCR system (BIO-RAD C1000 Thermal Cycler) under the following condition: an initial cycle for pre denaturation at $95{ }^{\circ} \mathrm{C}$ for $10 \mathrm{~min}$, followed by $\mathrm{n}$ cycles (cycles for each microorganism listed in Table 1) of denaturation at $95{ }^{\circ} \mathrm{C}$ for $30 \mathrm{~s}$, annealing (Tm for each microorganism listed in Table 1) $30 \mathrm{~s}$, and elongation at $72{ }^{\circ} \mathrm{C}$ for 1 minute, with a final cycle at $72{ }^{\circ} \mathrm{C}$ for $5 \mathrm{~min}$. The PCR products were visualized and photographed under UV light after electrophoresis for $45 \mathrm{~min}$ at $100 \mathrm{~V}$ through a $1 \%$ agarose gel (Fig. 1). Finally, the results were analyzed using descriptive statistics tests.

Table 1. The DNA sequence of PCR primer, Tm, cycles, and Length.

\begin{tabular}{|c|c|c|c|c|c|}
\hline $\begin{array}{l}\text { Name of } \\
\text { bactery }\end{array}$ & Nucleotide sequence (5'-3') & $\mathbf{T m}$ & Cycles & $\begin{array}{l}\text { Length } \\
\text { (bp) }\end{array}$ & Reference \\
\hline (U. urealyticum) & $\begin{array}{l}\text { F5 - TGGAGTTAAGTCGTAACAAG-3' } \\
\text { R5'-CTGAGATGTTTCACTTCACC-3 }\end{array}$ & 56 & 30 & 559 & (23) \\
\hline M. hominis)( & $\begin{array}{l}\text { F: 5'-CAATGGCTAATGCCGGATAC - } 3^{\prime} \\
\text { R: 5'-GGTACCGTCAGTCTGCAAT - } 3^{\prime}\end{array}$ & 56 & 30 & 335 & (24) \\
\hline C. trachomatis) & $\begin{array}{l}\text { F: 5'-CTAGGCGTTTGTACTCCGTCA-3' } \\
\text { R: 5'-TCCTCAGGAGTTTATGCACT-3' }\end{array}$ & 56 & 40 & 200 & (25) \\
\hline (N. gonorrhoeae) & $\begin{array}{l}\text { F: 5'-GCCTCGCGGCTTGGCTA-3' } \\
\text { R: 5'-GGCGCAGACGGTTACTTAAGCAGGA-3' }\end{array}$ & 57 & 35 & 694 & (26) \\
\hline (G. vaginalis) & $\begin{array}{l}\text { F: 5'-TTACTGGTGTATCACTGTAA-3' } \\
\text { R: 5'-CCGTCACAGGCTGAACAGT-3' }\end{array}$ & 55 & 30 & 330 & (27) \\
\hline (S. agalactiae) & $\begin{array}{l}\text { F: 5'-TTTCACCAGCTGTATTAGAAGTA-3' } \\
\text { R: 5'-GTTCCCTGAACATTATCTTTGAT-3' }\end{array}$ & 57 & 30 & 153 & (28) \\
\hline
\end{tabular}




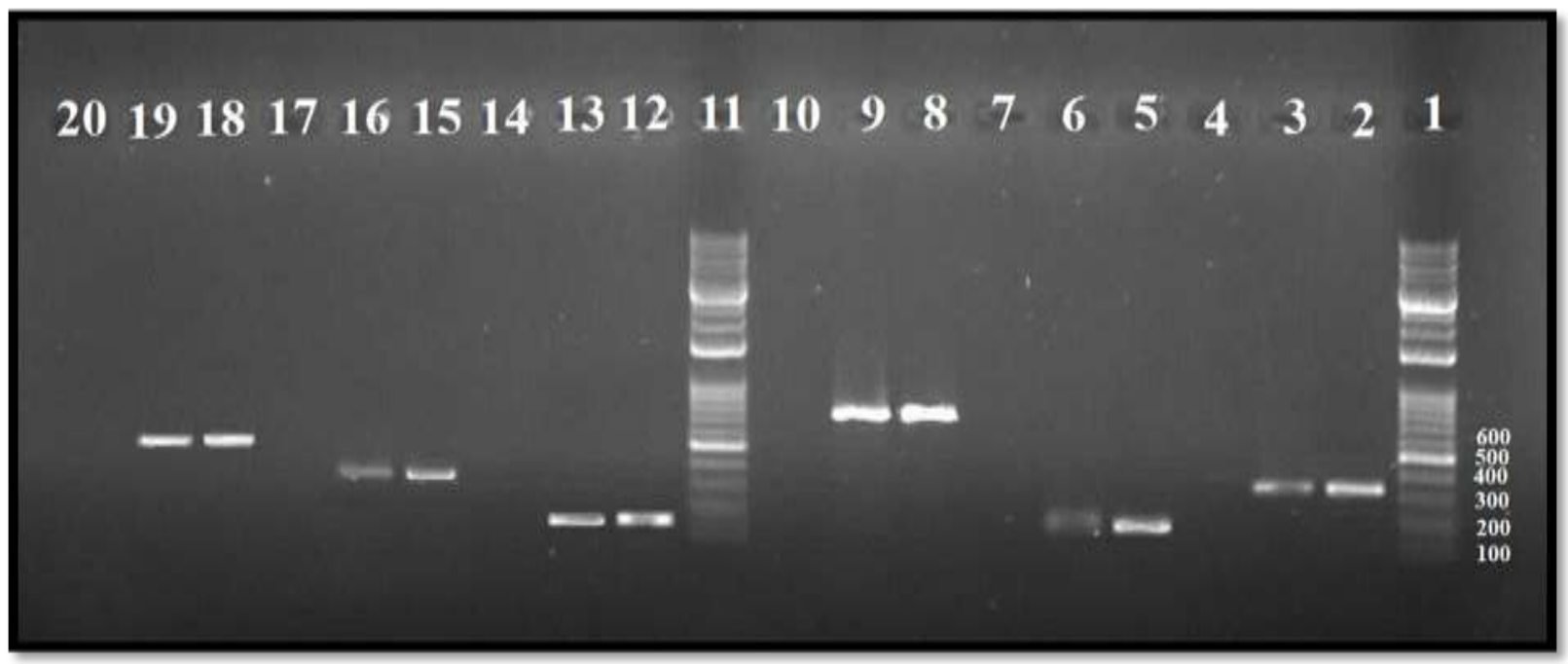

Fig. 1. Agarose gel electrophoresis of PCR amplified products.

Lane $1 \&$ 11: 100 bp ladder marker.

Lane 2: positive control for G. vaginalis (330 bp), Lane 3: positive sample for G. vaginalis (330 bp).

Lane 4: negative control for $G$. vaginalis (distilled water).

Lane 5: positive control for $C$. trachomatis (200 bp), Lane 6: positive sample for $C$. trachomatis (200 bp).

Lane 7: negative control for $C$. trachomatis (distilled water).

Lane 8 positive control for $N$. gonorrhoeae (694 bp), Lane 9: positive sample for $N$. gonorrhoeae (694 bp).

Lane 10: negative control for $N$. gonorrhoeae (distilled water).

Lane 12: positive control for $S$. agalactiae (153 bp), Lane 13: positive sample for S. agalactiae (153 bp).

Lane 14: negative control for $S$. agalactiae (distilled water).

Lane 15: positive control for M. hominis (335 bp), Lane 16: positive sample for M. hominis (335 bp).

Lane 17: negative control for $M$. hominis (distilled water).

Lane 18 positive control for $U$. urealyticum (559 bp), Lane 19: positive sample for $U$. urealyticum ( $559 \mathrm{bp}$ ).

Lane 20: negative control for $U$. urealyticum (distilled water).

\section{Results}

In this investigation, 280 women were recruited. Two groups of patients were identified based on positivity or negativity of HPV (118 HPV positive and 162 HPV negative subjects). According to the genotyping kit, 3 groups were identified: High-risk $(n=31,26.2 \%)$, low-risk $(\mathrm{n}=52,44 \%)$, and High-risk + low-risk $(\mathrm{n}=35$, 29.6\%). In HPV-positive and HPV-negative women, the mean age was 37 years, and most people were in the age range of 30-35 years, so there was no difference between the two groups with respect to age.

On the other hand, no significant difference was observed in history of pregnancies, marital status, and smoking in women with and without HPV, respectively (Table 2).

Table 2. Characteristics of studied population.

\begin{tabular}{ccccccccc}
\hline Characteristics & \multicolumn{2}{c}{ Smoking } & \multicolumn{2}{c}{ Marital Status } & \multicolumn{2}{c}{ History of Pregnancies } & \multicolumn{2}{c}{ Mean Age } \\
\hline \multirow{3}{*}{ Frequency } & $\begin{array}{c}\text { Hpv }+ \\
(\mathbf{n = 1 1 8})\end{array}$ & $\begin{array}{c}\text { Hpv- } \\
(\mathbf{n}=\mathbf{1 6 2})\end{array}$ & $\begin{array}{c}\mathbf{H p v}+ \\
(\mathbf{n = 1 1 8})\end{array}$ & $\begin{array}{c}\mathbf{H p v}- \\
(\mathbf{n = 1 6 2})\end{array}$ & $\begin{array}{c}\mathbf{H p v}+ \\
(\mathbf{n = 1 1 8})\end{array}$ & $\begin{array}{c}\mathbf{H p v}- \\
(\mathbf{n = 1 6 2})\end{array}$ & Hpv + & $\mathbf{H p v -}$ \\
\cline { 2 - 9 } & $5(4.23 \%)$ & $7(4.32 \%)$ & $83(70.33 \%)$ & $129(79.62 \%)$ & $51(43.22 \%)$ & $72(44.4 \%)$ & 37 & 37 \\
\hline
\end{tabular}

In HPV-positive group (118 cases), prevalence of $U$. urealyticum, M. hominis, $N$. gonorrhoeae, G. vaginalis, and S. agalactiae was $45(38.13 \%), 9(7.62 \%), 7(5.93 \%), 23$ $(19.49 \%), 1(0.84 \%)$ respectively. Among the two groups of low-risk and High-risk, the 
highest frequency of $N$. gonorrhoeae and $G$. vaginalis was observed in the low-risk group, and the highest frequency of $U$. urealyticum and $M$. hominis was observed in High-risk + low-risk, and High-risk group respectively.

In HPV-negative group (162 cases), the rate of infection with $U$. urealyticum, $M$. hominis, N. gonorrhoeae, G. vaginalis, and $S$. agalactiae was 48 (29.62\%), 10 (6.17\%), 5 (3.08\%), 26 (16.04\%), 1 (0.61\%) respectively. Among the two groups, there was only 1 infection with $C$. trachomatis $(0.84 \%)$, was seen in HPV-positive group (High-risk) (Table 3).
According to Table 4, the highest frequency of infection with $U$. urealyticum, M. hominis and G. vaginalis in both groups was seen in the 31-40 years' age category, while the lowest was seen in the older age range (up 50 years) and under 20 years. The highest infection with $N$. gonorrhoeae was observed in the group with and without HPV in 31-35 and 36-40 years, respectively. Also, the most coinfections were observed in both positive and negative HPV groups between $U$. urealyticum and $G$. vaginalis where the highest prevalence belonged to the negative HPV group (Table 5).

Table 3. Distribution of of bacteria in HPV negatives and positives.

\begin{tabular}{|c|c|c|c|c|c|}
\hline \multirow{2}{*}{$\begin{array}{l}\text { Name of } \\
\text { bacteria }\end{array}$} & \multirow{2}{*}{$\begin{array}{c}\text { HPV } \\
\text { negatives } \\
(n=162)\end{array}$} & \multicolumn{4}{|c|}{ HPV positive $(\mathrm{n}=118)$} \\
\hline & & $\begin{array}{c}\text { HR } \\
(n=31)\end{array}$ & $\begin{array}{c}\mathbf{L R} \\
(\mathrm{n}=52) \\
\end{array}$ & $\begin{array}{c}\text { HR+LR } \\
(n=35)\end{array}$ & $\begin{array}{c}\text { Total } \\
(n=118)\end{array}$ \\
\hline U. urealyticum & $48(29.62 \%)$ & $8(6.77 \%)$ & $18(15.25 \%)$ & $19(16.10 \%)$ & $45(38.13 \%)$ \\
\hline M. hominis & $10(6.17 \%)$ & $4(3.38 \%)$ & $2(1.69 \%)$ & $3(2.54 \%)$ & $9(7.62 \%)$ \\
\hline C. trachomatis & $0(0 \%)$ & $1(0.84 \%)$ & $0(0 \%)$ & $0(0 \%)$ & $1(0.84 \%)$ \\
\hline N. gonorrhoeae & $5(3.08 \%)$ & $2(1.69 \%)$ & $4(3.38 \%)$ & $1(0.84 \%)$ & $7(5.93 \%)$ \\
\hline G. vaginalis & $26(16.04 \%)$ & $5(4.23 \%)$ & $13(11.01 \%)$ & $5(4.23 \%)$ & $23(19.49 \%)$ \\
\hline S. agalactiae & $1(0.61 \%)$ & $0(0 \%)$ & $1(0.84 \%)$ & $0(0 \%)$ & $1(0.84 \%)$ \\
\hline $\mathbf{U u}+\mathbf{M h}$ & $2(1.23 \%)$ & $1(0.84 \%)$ & $0(0 \%)$ & $0(0 \%)$ & $1(0.84 \%)$ \\
\hline $\mathbf{U} \mathbf{u}+\mathbf{N g}$ & $1(0.61 \%)$ & $1(0.84 \%)$ & $1(0.84 \%)$ & $1(0.84 \%)$ & $3(2.54 \%)$ \\
\hline $\mathbf{U u}+\mathbf{G v}$ & $13(8.02 \%)$ & $2(1.69 \%)$ & $2(1.69 \%)$ & $3(2.54 \%)$ & $8(6.77 \%)$ \\
\hline $\mathrm{Ng}+\mathrm{Gv}$ & $0(0 \%)$ & $0(0 \%)$ & $2(1.69 \%)$ & $0(0 \%)$ & $2(1.69 \%)$ \\
\hline $\mathbf{M h}+\mathbf{G v}$ & $2(1.23 \%)$ & $0(0 \%)$ & $0(0 \%)$ & $1(0.84 \%)$ & $1(0.84 \%)$ \\
\hline $\mathrm{Mh}+\mathrm{Ng}$ & $1(0.61 \%)$ & $0(0 \%)$ & $0(0 \%)$ & $0(0 \%)$ & $0(0 \%)$ \\
\hline $\mathbf{U}+\mathbf{m h}+\mathrm{gv}$ & $1(0.61 \%)$ & $1(0.84 \%)$ & $2(1.69 \%)$ & $0(0 \%)$ & $3(2.54 \%)$ \\
\hline Uu+mh+ng & $1(0.61 \%)$ & $0(0 \%)$ & $0(0 \%)$ & $0(0 \%)$ & $0(0 \%)$ \\
\hline Uu+gv+ng & $1(0.61 \%)$ & $0(0 \%)$ & $0(0 \%)$ & $0(0 \%)$ & $0(0 \%)$ \\
\hline $\mathbf{C t}+\mathbf{M h}+\mathbf{G v}$ & $0(0 \%)$ & $1(0.84 \%)$ & $0(0 \%)$ & $0(0 \%)$ & $1(0.84 \%)$ \\
\hline
\end{tabular}

*Uu: U. urealyticum Mh: M. hominis $\mathrm{Ng}$ : N. gonorrhoeae Gv: G. vaginalis $\mathrm{Ct}$ : C. trachomatis

Table 4. Frequency of bacteria in different age groups (in women with and without HPV infection).

\begin{tabular}{|c|c|c|c|c|c|c|c|c|c|c|c|c|}
\hline \multirow{2}{*}{$\begin{array}{l}\text { Age } \\
\text { groups }\end{array}$} & \multicolumn{2}{|c|}{ U.urealyticum } & \multicolumn{2}{|c|}{ M. hominis } & \multicolumn{2}{|c|}{ C. trachomatis } & \multicolumn{2}{|c|}{ N. gonorrhoeae } & \multicolumn{2}{|c|}{ G. vaginalis } & \multicolumn{2}{|c|}{ S. agalactiae } \\
\hline & Hpv+ & Hpv- & Hpv+ & Hpv- & Hpv+ & Hpv- & Hpv+ & Hpv- & Hpv+ & Hpv- & Hpv+ & Hpv- \\
\hline $\begin{array}{c}\text { Under } \\
20 \\
\end{array}$ & 0 & 1 & 0 & 0 & 0 & 0 & 0 & 0 & 1 & 0 & 0 & 0 \\
\hline $20-30$ & 14 & 11 & 3 & 2 & 0 & 0 & 3 & 1 & 5 & 4 & 1 & 0 \\
\hline $31-40$ & 26 & 31 & 5 & 8 & 1 & 0 & 3 & 3 & 15 & 21 & 0 & 1 \\
\hline $41-50$ & 5 & 5 & 1 & 0 & 0 & 0 & 1 & 1 & 2 & 1 & 0 & 0 \\
\hline Up 50 & 0 & 0 & 0 & 0 & 0 & 0 & 0 & 0 & 0 & 0 & 0 & 0 \\
\hline
\end{tabular}


Table 5. Frequency of common infections in different age groups

\begin{tabular}{|c|c|c|c|c|c|c|c|c|}
\hline \multirow{2}{*}{$\begin{array}{l}\text { Age groups } \\
\text { Common } \\
\text { infection }\end{array}$} & \multicolumn{2}{|c|}{$20-30$} & \multicolumn{2}{|c|}{$31-40$} & \multicolumn{2}{|c|}{$41-50$} & \multicolumn{2}{|c|}{ Total } \\
\hline & Hpv+ & Hpv- & Hpv+ & Hpv- & Hpv+ & Hpv- & Hpv+ & Hpv- \\
\hline Uu+Mh & 1 & & & 2 & & & 1 & 2 \\
\hline $\mathrm{Uu}+\mathrm{Ng}$ & & & 3 & & & & 3 & 0 \\
\hline $\mathbf{U u}+\mathbf{G v}$ & 3 & 5 & 3 & 7 & 1 & 1 & 7 & 13 \\
\hline $\mathrm{Ng}+\mathrm{Gv}$ & 2 & & & & & & 2 & 0 \\
\hline $\mathbf{M h}+\mathbf{G v}$ & 1 & & & 2 & & & 1 & 2 \\
\hline $\mathrm{Mh}+\mathrm{Ng}$ & & 1 & & & & & 0 & 0 \\
\hline $\mathrm{Uu}+\mathrm{mh}+\mathrm{gv}$ & 1 & 1 & 2 & & & & 3 & 1 \\
\hline Uu+mh+ng & & & & 1 & & & 0 & 1 \\
\hline Uu+gv+ng & & & & 1 & & & 0 & 1 \\
\hline $\mathbf{C t}+\mathbf{M h}+\mathbf{G v}$ & & & 1 & & & & 1 & 0 \\
\hline
\end{tabular}

* In this study, no common infections were observed in age groups under 20 and over 50 years

\section{Discussion}

Genital microorganisms can be transmitted through human sexual contacts and cause sexually transmitted infections (STIs) and serious consequences. One of them is HPV that, depending on their oncogenic potential, is divided into high-risk and low-risk groups. Many pathogens act as cofactors interacting with HPV in the development of pre-cancer or cancer of the cervix and can directly or indirectly result in the development and progression of cervical lesions. To detect these microorganisms, Polymerase Chain Reaction (PCR) was selected which is fast, sensitive, specific, and easy. In this study, the correlation between infection of $M$. hominis, $U$. urealyticum, C. trachomatis, $N$. gonorrhoeae, $G$. vaginalis and $S$. agalactiae in people with HPV and without HPV was evaluated by PCR. According to the results, the prevalence rate of $U$. urealyticum, M. hominis, G. vaginalis and $S$. agalactiae, in both groups (with and without HPV) was similar, with no significant difference. In contrast, infection with $C$. trachomatis was present only in the HPV-positive group. Also, a higher prevalence of $N$. gonorrhoeae was seen in HPV-positive women compared to HPVnegative women. So, there was a correlation between HPV-positive, especially high-risk, with C. trachomatis and $N$. gonorrhoeae.
In addition, common infections (triple and double infections) in groups with and without HPV were relatively high (19 $(16.1 \%)$ and 22 $(13.5 \%)$ respectively), and the highest prevalence of double infection was $U$. urealyticum and $G$. vaginalis, (8(6.77\%) $13(8.02 \%)$ respectively) and the highest prevalence of triple infection was in women with HPV between $U$. urealyticum, $M$. hominis and G. vaginalis $(3(2.54 \%))$.

On the other hand, no significant correlation between women with and without HPV, and these microorganisms' infection and the factors including smoking, marital status, and history of pregnancies, was found.

Based on Table 3, the highest frequency of HPV and the most frequent microorganisms in groups with and without HPV were in 20-40 years, and in women over the age of 40 , there was seen less frequency of HPV and these bacteria, possibly due to a decrease in sexual activity in older women.

In numerous studies, the frequency of these microorganisms has been investigated, such as studies that reported $21.3 \%$ and $14.9 \%$ prevalence for $G$. vaginalis in HPV-positive group and HPV-negative group. Their investigation was carried out on intraepithelial 
neoplasia (CIN) grade I (low-grade squamous lesion), and the methodology in detection of HPV infection and Gardnerella vaginalis was based on the study of Schneider et al. and finding of clue cells respectively (29). Differences in the results of their investigation and those of our study may be due to their methodology and the samples used.

In other study, in samples obtained from vaginal canal and uterine cervix of female sex workers, $G$. vaginalis was observed to be $76.9 \%$ (10.13) and $79.6 \%$ (43.54), and C. trachomatis was reported to be $38.5 \%$ (5.13) and $22.2 \%$ (12.54), in the group with and without HPV (30). High rate of genital agents such as $G$. vaginalis and $C$. trachomatis in their study can be due to the characteristics of their studied population (sex workers) since they were constantly exposed to sexually transmitted agents.

Infection of $C$. trachomatis in women with abnormal cytology in the study by Finan showed a high rate: 21.44 in HPV-positive as compared to 11.77 in HPV-negative cases. There was higher prevalence of this bacterium in the 31-40 age group category (22). Since infection with $C$. trachomatis facilitates the development of invasive squamous cell carcinoma (22), high frequency of this microorganism in abnormal cytology in their study is reasonable. But in our study, normality or abnormality of samples was not determined. In the present study, only 1 case was positive for $C$. trachomatis which was in the age 31-40, similar to Finan's study.

In a study by Biernat-Sudolska $\mathrm{M}$, frequency of $U$. urealyticum and $M$. hominis in HPVpositive women $(\mathrm{n}=58)$ was $12(20.6 \%)$ and $1(1.72 \%)$ (10). Existence of $U$. urealyticum in the group with HPV in their study was higher than that in the control group, in contrast to the finding in our study which may be due to the type of their samples (abnormal cervix and cervical carcinomas).

Marianna Martinelli et al. also evaluated some of STI pathogens in women Pap smear with an abnormal cervical cytology and reported prevalence of $6(5.26 \%), 2(1.75 \%), 0(0 \%)$ and $0(0 \%)$ in $U$. urealyticum, $M$. hominis, $C$. trachomatis and $N$. gonorrhoeae respectively in high-risk HPVs (31). The prevalence of $U$. urealyticum, $M$. hominis, $C$. trachomatis and $N$. gonorrhoeae in our study was higher $(25.8 \%$, $12.9 \%, 3.2 \%, 6.4 \%$ respectively) in high-risk HPV group, as compared with the study conducted by Marianna Martinelli.

Another study in Poland detected 4 cases $U$. urealyticum in HPV-positive women (31 cases) two of whom were hemodialysed women and 2 other cases were in the control group (non-hemodialysis women) (32). In our investigation, higher frequency of $U$. urealyticum was detected that may be because of the bigger sample size in our study. On the other hand, their study was performed on hemodialysed women that may have affected the rate of $U$. urealyticum.

In a study by Prete et al., detection of STI pathogens was performed by multiplex Real-Time PCR in vaginal and cervical specimens showing that the prevalence of $U$. urealyticum, $M$. hominis, $C$. trachomatis and $N$. gonorrhoeae was 30 (2.36\%), 15 (1.18\%), 5 $(0.39 \%)$, and $1(0.08 \%)$ respectively. Also, coinfection prevalence of $U$. urealyticum $+M$. hominis in their study was $10(0.79 \%)$ (33). Higher frequency of $U$. urealyticum, M. hominis and $N$. gonorrhoeae, and lower prevalence of $C$. trachomatis in the present study (negative HPV + positive HPV) compared with the study by Prete et al. may be associated with differences in the number and kind of samples, technique, or even race.

In this study no significant association was found between HPV and bacteria such as $G$. vaginalis and $S$. agalactiae, and the results indicated that some of analyzed bacteria ( $U$. urealyticum, M. hominis and G. vaginalis) could be part of normal flora in Iranian women. On the other hand, the results demonstrated that $C$. trachomatis and especially $N$. gonorrhoeae are strongly associated with HPV infection, and HPV infection may increase susceptibility to other infections like $C$. trachomatis and especially $N$. gonorrhoeae. This investigation confirmed that screening for genital agents may be important to rapid treatment. 


\section{Acknowledgements}

The authors would like to kindly thank the Student Research Committee of Bam University of Medical Sciences (code of grant 97.29), which provided funding for this study by a Bam

\section{References}

1. Stanley MA, Pett MR, Coleman N. HPV: from infection to cancer. Biochem Soc Trans. 2007;35(Pt 6):1456-60.

2. Houlihan CF, Larke NL, Watson-Jones D, Smith-McCune KK, Shiboski S, Gravitt PE, et al. HPV infection and increased risk of HIV acquisition. A systematic review and metaanalysis. AIDS. 2012;26(17).

3. Lu H, Jiang P-C, Zhang X-D, Hou W-J, Wei $\mathrm{Z}-\mathrm{H}, \mathrm{Lu} \mathrm{J}-\mathrm{Q}$, et al. Characteristics of bacterial vaginosis infection in cervical lesions with high risk human papillomavirus infection. Int J Clin Exp Med. 2015;8(11):21080-21088.

4. Lee JE, Lee S, Lee H, Song Y-M, Lee K, Han MJ, et al. Association of the vaginal microbiota with human papillomavirus infection in a Korean twin cohort. PloS one. 2013;8(5):e63514.

5. Nardis C, Mosca L, Mastromarino P. Vaginal microbiota and viral sexually transmitted diseases. Ann Ig. 2013;25(5):443-56.

6. Gallo MF, Macaluso M, Warner L, Fleenor ME, Hook III EW, Brill I, et al. Bacterial vaginosis, gonorrhea, and chlamydial infection among women attending a sexually transmitted disease clinic: a longitudinal analysis of possible causal links. Ann Epidemiol. 2012;22(3):213-20.

7. Panchaud C, Singh S, Feivelson D, Darroch JE. Sexually transmitted diseases among adolescents in developed countries. Fam Plann Perspect. 2000;32(1):24-32.

8. Horner P, Donders G, Cusini M, Gomberg M, Jensen J, Unemo M. Should we be testing for urogenital Mycoplasma hominis, Ureaplasma parvum and Ureaplasma urealyticum in men and women?-a position statement from the European STI Guidelines Editorial Board. J Eur Acad Dermatol Venereol. 2018;32(11):1845-1851.

9. Lukic A, Canzio C, Patella A, Giovagnoli M, Cipriani P, Frega A, et al. Determination of cervicovaginal microorganisms in women with abnormal cervical cytology: the role of
University of Medical Sciences research and technology grant.

The authors declare that they have no conflict of interest.

Ureaplasma urealyticum. Anticancer Res. 2006;26(6C):4843-9.

10. Biernat-Sudolska M, Szostek S, RojekZakrzewska D, Klimek M, Kosz-Vnenchak M. Concomitant infections with human papillomavirus and various mycoplasma and ureaplsasma species in women with abnormal cervical cytology. Adv Med Sci. 2011;56(2):299-303.

11. Mousavi A, Farhadifar F, Mirnejad R, Ramazanzadeh R. Detection of genital mycoplasmal infections among infertile females by multiplex PCR. Iran $\mathrm{J}$ Microbiol. 2014;6(6):398-403.

12. Najar Peerayeh S, Samimi R. Detection of ureaplasma urealyticum in clinical samples from infertile women by polymerase chain reaction. Iranian Journal of Pharmacology and Therapeutics. 2007;6(1):23-26.

13. Hartmann M. Genital mycoplasmas. JDDG: Journal der Deutschen Dermatologischen Gesellschaft. 2009;7(4):371-7.

14. O'Connell CM, Ferone ME. Chlamydia trachomatis genital infections. Microb Cell. 2016;3(9):390-403.

15. Whiley DM, Tapsall JW, Sloots TP. Nucleic acid amplification testing for Neisseria gonorrhoeae: an ongoing challenge. $\mathrm{J}$ Mol Diagn. 2006;8(1):3-15.

16. Rostami MN, Rashidi BH, Habibi A, Nazari $\mathrm{R}$, Dolati M. Genital infections and reproductive complications associated with Trichomonas vaginalis, Neisseria gonorrhoeae, and Streptococcus agalactiae in women of Qom, central Iran. Int $\mathrm{J}$ Reprod Biomed. 2017;15(6):357-366.

17. Edwards MS, Baker CJ. Streptococcus Agalactiae (group B streptococcus). Mandel GL, Bennett JE, Dolin R eds. Principles and Practice of Infectious Diseases 4th ed. New York: Churchill Livingston Inc. 1995:1835-1845. 
18. Catlin BW. Gardnerella vaginalis: characteristics, clinical considerations, and controversies. Clin Microbiol Rev. 1992;5(3):213-37.

19. Amaya RA, Al-Dossary F, Demmler GJ. Gardnerella vaginalis bacteremia in a premature neonate. J Perinatol. 2002;22(7):585-7.

20. Papp JR, Schachter J, Gaydos CA, Van Der Pol B. Recommendations for the laboratorybased detection of Chlamydia trachomatis and Neisseria gonorrhoeae-2014. MMWR Recomm Rep. 2014;63(RR-02):1-19.

21. Teng K, Li M, Yu W, Li H, Shen D, Liu D. Comparison of PCR with culture for detection of Ureaplasma urealyticum in clinical samples from patients with urogenital infections. J Clin Microbiol. 1994;32(9):2232-4.

22. Finan R, Tamim H, Almawi W. Identification of Chlamydia trachomatis DNA in human papillomavirus (HPV) positive women with normal and abnormal cytology. Archives of gynecology and obstetrics. 2002;266(3):168-71.

23. Mirnejad R, Amirmozafari N, Kazemi B. Simultaneous and rapid differential diagnosis of Mycoplasma genitalium and Ureaplasma urealyticum based on a polymerase chain reaction-restriction fragment length polymorphism. Indian $\mathrm{J}$ Med Microbiol. 2011;29(1):33-6.

24. Ataee RA, Golmohammadi R, Alishiri GH, Mirnejad R, Najafi A, Esmaeili D, et al. Simultaneous Detection of Mycoplasma pneumoniae, Mycoplasma hominis and Mycoplasma arthritidis in Synovial Fluid of Patients with Rheumatoid Arthritis by Multiplex PCR. Arch Iran Med. 2015;18(6):345-50.

25. Hajikhani B, Motallebi T, Norouzi J, Bahador A, Bagheri R, Asgari S, et al. Classical and molecular methods for evaluation of Chlamydia trachomatis infection in women with tubal factor infertility. J Reprod Infertil. 2013;14(1):29-33.

26. Karimpour A, Esmaeelnezhad Moghadam A, Moslemizadeh N, Mousanezhad N, Peyvandi $\mathrm{S}$, Gahandar $\mathrm{M}$. Incidence and main causes of infertility in patients attending the infertility center of Imam khomeini hospital in 2002-2004. Journal of Mazandaran University of Medical Sciences. 2005;15(49):44-9.

27. Malaguti N, Bahls LD, Uchimura NS, Gimenes F, Consolaro MEL. Sensitive detection of thirteen bacterial vaginosis-associated agents using multiplex polymerase chain reaction. BioMed research international. 2015;2015.

28. Fouad M, Zakaria S, Metwally L, AboulAtta H, Kamel M. Detection of Maternal Colonization of Group B Streptococcus by PCR Targeting $\mathrm{cfb}$ and scpB Genes. Journal of Microbiology, Biotechnology and Food Sciences. 2016;6(1):713.

29. Murta EFC, Souza MAHd, Araújo Júnior E, Adad SJ. Incidence of Gardnerella vaginalis, Candida sp and human papilloma virus in cytological smears. Sao Paulo Med J. 2000;118(4):105-8.

30. Lugo LZ, Jacob C, Machado AP, Almeida FG, Ávila LS, Prata T, et al. Human papillomavirus and coinfections with Chlamydia trachomatis, Gardnerella vaginalis, and Trichomonas vaginalis in self-collected samples from female sex workers in the Central-Western region of Brazil. Jornal Brasileiro de Patologia e Medicina Laboratorial. 2018;54(1):46-51.

31. Martinelli M, Musumeci R, Sechi I, Sotgiu G, Piana A, Perdoni F, et al. Prevalence of Human Papillomavirus (HPV) and Other Sexually Transmitted Infections (STIs) among Italian Women Referred for a Colposcopy. Int J Environ Res Public Health. 2019;16(24):5000.

32. Ekiel A, Pietrzak B, Wiechuła B, Aptekorz M, Mazanowska N, Rady D, et al. Urogenital mycoplasmas and human papilloma virus in hemodialysed women. The Scientific World Journal. 2013;2013:(4);659204.

33. Del Prete R, Ronga L, Lestingi M, Addati G, Angelotti UF, Di Carlo D, et al. Simultaneous detection and identification of STI pathogens by multiplex Real-Time PCR in genital tract specimens in a selected area of Apulia, a region of Southern Italy. Infection. 2017;45(4):469-477. 